\title{
The Role of Waste Glass Powder During the Hydration Process of Composite Cementitious Materials
}

\author{
Shuhua LIU ${ }^{1,2}{ }^{*}$, Weiwei HAN ${ }^{1}$, Wei ZHOU $^{1}$ \\ ${ }^{1}$ State Key Laboratory of Water Resources and Hydropower Engineering Science, Wuhan University, Wuhan 430072, \\ China \\ ${ }^{2}$ Department of Civil, Environmental and Geomatic Engineering, University College London, Gower Street, London, \\ WCIE 6BT, U.K. \\ cross $^{\text {ref }}$ http://dx.doi.org/10.5755/j01.ms.22.4.13210
}

Received 24 September 2015; accepted 19 December 2015

\begin{abstract}
The role of waste glass powder (GP) during the hydration process of composite cementitious materials was investigated by using mercury intrusion porosimetry (MIP), X-ray diffraction (XRD) and scanning electron microscopy (SEM) techniques. The compressive strength was also tested. The results indicate that the chemical activity of GP is low. But the pozzolanic reactivity of GP greatly improves with its fineness and the elevated curing temperature, which contributes to improving the mechanical strength. The hydration process of composite cementitious material containing GP is similar to that of pure cement. With the increase of GP content in the composite cement, the occurring time of second exothermic improves, but the value of second exothermic peak and the cumulative hydration heat reduce. The characteristic pore size of pastes containing GP decreases over curing age, which significantly improves their strength. GP does not modify the type of hydration products of composite cementitious material. The microstructure of hardened pastes containing GP is dense due to the generation of $\mathrm{C}-\mathrm{S}-\mathrm{H}$ gel with a low $\mathrm{Ca} / \mathrm{Si}$ ratio. There is a reaction ring along GP with high fineness, which can enhance the interfacial transition zone to avoid ASR.

Keywords: waste glass powder, hydration properties, compressive strength, microstructure.
\end{abstract}

\section{INTRODUCTION}

Waste glass are largely generated from bottles, jars, windows and windshields, bulbs, cathode ray tubes, etc. In 2005 , approximately 12.8 million tons of waste glass was disposed in the United States, yet only 2.75 million tons were recycled [1]. In China, approximately 4.7 million tons of waste glass is discharged every year [2]. However, not all waste glass can be recycled to produce new glass because of impurities, high cost, and various colors [3]. For instance, 1.65 million tons of waste glasses are abandoned in U.K. every year because of unsuitability for recycling [4]. Approximately 4500 tons of waste glass were recycled annually, the recycled percentage was $3.3 \%$ and the remaining $96.7 \%$ was sent to landfill for direct dumping [5]. The landfill treatment is carried out at tremendous cost, e.g. the New York City pays Material Recycling Facilities up to $\$ 45$ per ton for the disposal of the glass, and the annual amount of waste glass generated exceeds 100,000 tons [6].

The amount of waste glass is gradually increased with the growth in number or quantity of glass products, which calls for more landfill sites. Furthermore, waste glass is an unbiodegradable material, thus landfill cannot provide an environmental friendly solution. It is imperative to figure out an efficient and environmentally friendly way to dispose waste glass. Cement-based materials, which are largely used in civil engineering, have little restriction on the quality of raw materials, thus providing an efficient way to massively recycle industrial solid waste. Since

\footnotetext{
* Corresponding author. Tel.: +86-27-68772233; fax: +86-27-68772310

E-mail address: shliu@whu.edu.cn (S. Liu)
}

1970s, many researchers have studied the incorporation of waste glass as aggregate or cementitious material in concrete [7]. Kou et al. [8] focused on the use of waste glass as aggregate to produce self-compacting concrete. They found that the chloride penetration resistance improved and the air content of concrete increased with the increase of glass aggregate replacement rate. However, a major concern regarding the use of glass as aggregate in concrete is the chemical reaction between the silica-rich glass particles and the alkali in the pore solution of concrete, which may cause alkali-silica reaction (ASR) expansion and thus reduce the stability and the durability. Rachida et al. [9] revealed that only glass particle with the size more than $1 \mathrm{~mm}$ could lead to harmful expansion related to ASR. Other study indicated [10] that glass powder with an average size of $300 \mu \mathrm{m}$ did not show any pozzolanic behavior. Shao et al. [11] and Rachida et al. [12] stated briefly that ground glass powder with the size less than $38 \mu \mathrm{m}$ exhibited a pozzolannic behavior. The smaller glass particle led to higher reactivity with lime, higher compressive strength and lower ASR expansion of concrete. It means that the ASR can be reduced or even eliminated if the particle size of GP is small enough. Because of high content of $\mathrm{SiO}_{2}$ and $\mathrm{CaO}$, waste glass can exhibit a remarkably pozzolanic behavior if ground finely enough. It can substitute partial cement and act as a supplementary cementitious material [13]. Rachida et al. [14] revealed that pozzolanic reaction of waste glass powder led to the formation of C-S-H gel with a low $\mathrm{Ca} / \mathrm{Si}$ ratio. This $\mathrm{C}-\mathrm{S}-\mathrm{H}$ gel could increase the density of the paste microstructure and lead to the decrease of porosity and permeability. 
This paper mainly focuses on figuring out the hydration activity and the strength development of paste and mortar containing GP with different fineness and under various curing conditions. Besides of the strength, microstructure of the mortars is investigated by using XRD, SEM as well as MIP. The hydration heat evolution rate and cumulative hydration heat of composite cementitious material containing GP were also measured by an isothermal calorimeter (TAM Air).

\section{EXPERIMENTAL}

42.5 Ordinary Portland cement which complies with the Chinese standard GB175-2007 is used in this study. GP is made of waste glass bottles which are crushed and ground in a ball mill after being washed and dried. In contrast with spherical fly ash particles, most GP particles with smooth surface morphology are irregular angular, blocky and clastic. The chemical compositions of cement and GP used are listed in Table 1.

Table 1. Chemical composition of cement and GP/mass, \% \begin{tabular}{|l|l|l|l|l|l|l|l|l|}
\hline Compositions & $\mathrm{SiO}_{2}$ & $\mathrm{Al}_{2} \mathrm{O}_{3}$ & $\mathrm{CaO}$ & $\mathrm{Fe}_{2} \mathrm{O}_{3}$ & $\mathrm{MgO}$ & $\mathrm{SO}_{3}$ & $\mathrm{~K}_{2} \mathrm{O}$ & $\mathrm{Na}_{2} \mathrm{O}$ \\
\hline
\end{tabular} \begin{tabular}{|l|l|l|l|l|l|l|l|l|}
\hline Cement & 24.55 & 4.66 & 58.77 & 3.36 & 0.04 & 3.33 & 0.99 & 0.24 \\
\hline
\end{tabular}

\begin{tabular}{l|l|l|l|l|l|l|l|l|} 
GP & 69.17 & 2.94 & 10.25 & 1.47 & 1.16 & 0.11 & 1.26 & 12.13 \\
\hline
\end{tabular}

From Table 1, GP contains large quantities of active $\mathrm{SiO}_{2}$ which contributes to the pozzolanic activity when ground to certain fineness. As for the effect of fineness on the strength of mortar, this work selects the GP with two finenesses whose specific surface area are $325 \mathrm{~m}^{2} / \mathrm{kg}$ and $658 \mathrm{~m}^{2} / \mathrm{kg}$ as coarse glass powder (CGP) and fine glass powder (FGP) respectively. The hydration process of composite cementitious materials was studied under standard $\left(20^{\circ} \mathrm{C}\right)$ and $40{ }^{\circ} \mathrm{C}$ steam curing conditions.

The mix proportions of the pastes and mortars are illustrated in Table 2 and Table 3 respectively. Pastes with water-to-binder ratio of 0.5 were prepared for hydration heat test, MIP, XRD and SEM analysis. As the mechanical strength of the pastes is unsteady, mortars with binder-tosand ratio of $1: 3$ and water-to-binder ratios of 0.5 and 0.3 were prepared for compressive strength test. In accordance with GB/T17671-1999, $100 \mathrm{~mm}$ cubic specimens were prepared with the only modification in the fineness and curing temperature. They were cured under higher than $90 \% \mathrm{RH}$ and $20 \pm 1{ }^{\circ} \mathrm{C}$ for 24 hours before demolded. Each half of the specimens were cured under standard and $40{ }^{\circ} \mathrm{C}$ steam curing conditions.

Table 2. Mix proportion of the pastes/mass, \%

\begin{tabular}{|c|c|c|c|}
\hline Samples & Cement & FGP & Water \\
\hline Cement & 100 & 0 & 50 \\
\hline GP20 & 80 & 20 & 50 \\
\hline GP40 & 60 & 40 & 50 \\
\hline
\end{tabular}

A battery solution type compression testing machine WAY-2000 was used to measure compressive strength at 3 and 90 days. And the cores from the crushed paste specimens were collected and stored in absolute ethylalcohol in order to terminate the hydration. Then, in order to be used for XRD analyses, the samples were ground in an agate mortar and dried under $60^{\circ} \mathrm{C}$ drying condition for 3 hours to avoid carbonization. MIP and SEM techniques were also employed to characterize the pore structure of pastes and morphology of mortars containing different dosages of waste glass powder under different curing conditions.

Table 3. Mix proportions of the mortars/g

\begin{tabular}{|c|c|c|c|c|c|}
\hline W/B & GP $/ \%$ & Cement & GP & Water & Sand \\
\hline 0.3 & 0 & 450 & 0 & 135 & 1350 \\
\hline 0.3 & 20 & 360 & 90 & 135 & 1350 \\
\hline 0.3 & 40 & 270 & 180 & 135 & 1350 \\
\hline 0.5 & 0 & 450 & 0 & 225 & 1350 \\
\hline 0.5 & 20 & 360 & 90 & 225 & 1350 \\
\hline 0.5 & 40 & 270 & 180 & 225 & 1350 \\
\hline
\end{tabular}

\section{RESULTS AND DISCUSSION}

\subsection{Hydration heat evolution}

The hydration heat evolution rate and cumulative hydration heat of the composite cementitious materials containing GP at $20{ }^{\circ} \mathrm{C}$ are shown in Fig. 1.

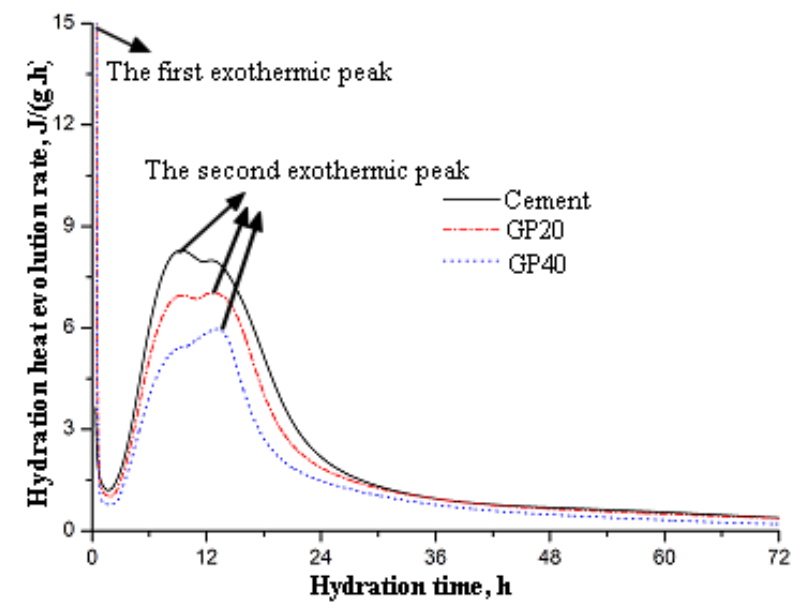

a

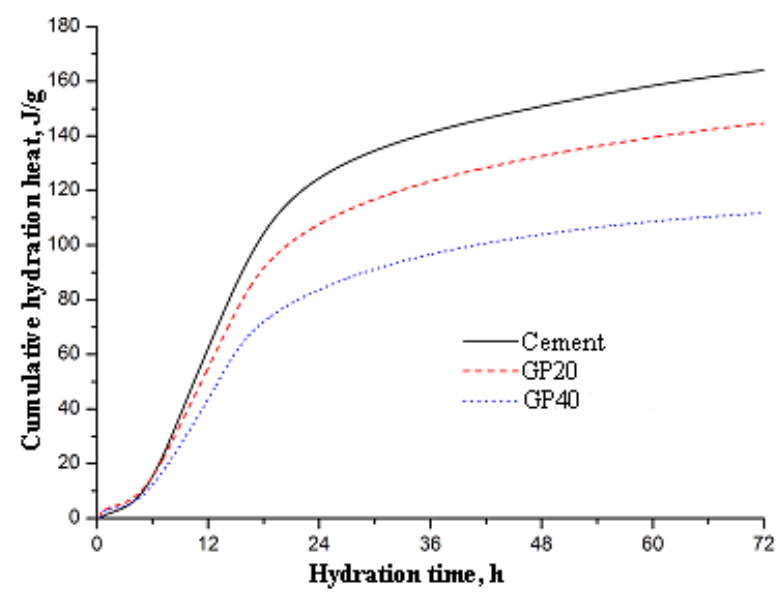

b

Fig. 1. $a$-hydration heat evolution rate; $b$-cumulative hydration heat of the composite cementitious materials

The hydration process of composite cementitious materials incorporating GP is similar to that of the pure cement. The initial hydration heat evolution rate of GP pastes which corresponds to the first peak of the curve is higher than that of the pure cement. This may attribute to that the water content in the system is relatively higher when GP partially replaces cement, thus there is more water participating in the initial hydration with cement. The reaction between water and cement releases the 
surface energy and promote the fast reaction of aluminates, leading to the improvement of hydration rate of the system within a short time. Then the hydration heat evolution rate decreases rapidly, and the reaction enters the second stage, i.e. dormant period. For pure cement pastes and the pastes containing $20 \%$ and $40 \% \mathrm{GP}$, the durations of the induction period increase from $1.678 \mathrm{~h}$ to $1.858 \mathrm{~h}$ and $1.874 \mathrm{~h}$, respectively, and it also postpones the appearance of the second exothermic peak $(9.345 \mathrm{~h}, 12.62 \mathrm{~h}, 13.114 \mathrm{~h})$ (Fig. 1 a). Furthermore, a reduction in the total hydration heat with increasing dosage of GP can be also observed (Fig. $1 \mathrm{~b}$ ). This may be caused by the increase of effective water due to increase of the replacement ratio of GP, which results in relatively decreased concentration of $\mathrm{Ca}^{2+}$ in pore solution. Therefore, the dormant period in which the concentration of $\mathrm{Ca}^{2+}$ need to reach saturation state before further hydration of GP is prolonged and the occurring time of the second exothermic peak is delayed.

Compared with pure cement, the hydration heat evolution rate and total hydration heat of the cementitious system containing GP reduce, which weakens the intensity of hydration reaction as a whole. The similar curves illustrate that GP is inert and the activity is very low in the early hydration stage. But the hydration reduces the ASR risk, and hereby improves the durability of hardened cement paste in the long run.

\subsection{Compressive strength}

Table 4 shows the compressive strength development of mortars with different content and fineness of GP under two curing conditions.

Table 4. Compressive strength of mortars under standard and $40{ }^{\circ} \mathrm{C}$ steam curing conditions / $\mathrm{MPa}$

\begin{tabular}{|c|c|c|c|c|c|}
\hline \multirow{2}{*}{ Sample } & \multirow{2}{*}{ W/B } & \multicolumn{2}{|c|}{ Standard curing } & \multicolumn{2}{c|}{ Steam curing } \\
\cline { 3 - 6 } & & 3 days & 90 days & 3 days & 90 days \\
\hline GP-0 & 0.3 & 44.02 & 64.11 & 44.48 & 67.66 \\
\hline FGP-20 & 0.3 & 33.61 & 67.25 & 43.69 & 73.99 \\
\hline FGP-40 & 0.3 & 21.65 & 61.32 & 30.83 & 74.23 \\
\hline CGP-20 & 0.3 & 31.58 & 60.29 & 40.06 & 70.36 \\
\hline CGP-40 & 0.3 & 16.39 & 53.63 & 26.85 & 64.23 \\
\hline GP-0 & 0.5 & 31.09 & 61.43 & 34.48 & 58.36 \\
\hline FGP-20 & 0.5 & 18.58 & 42.36 & 26.74 & 44.64 \\
\hline FGP-40 & 0.5 & 13.48 & 38.77 & 19.91 & 41.73 \\
\hline CGP-20 & 0.5 & 14.67 & 39.60 & 17.09 & 41.30 \\
\hline CGP-40 & 0.5 & 8.82 & 34.35 & 12.14 & 37.25 \\
\hline
\end{tabular}

The control sample has a higher strength than those containing GP at all curing ages under standard curing conditions. This phenomenon can be attributed to the low GP reaction level and the increase in water to binder ratio at normal temperature. Elevated temperature can advance and improve the reactivity of GP and accelerate its pozzolanic reaction, leading to the generation of more C-S-H gel, which contributes to the strength development. GP is less reactive than cement, thus the latter is prior to reacting. The prior hydration of cement could make the $\mathrm{pH}$ value a little higher than 13.0 in a short time [15]. The high alkalinity in matrix breaks down the silica structure of the glass, and more silica and aluminum dissolve and participate in the pozzolanic reaction [16].

As for the fineness, small particles can dissolve in the pore solution, and then participate in the pozzolanic reaction to form stable C-S-H gel with low alkalinity [17]. With respect to large GP particles, hydroxide ions generally erode and dissolve the particles, then the released $\mathrm{SiO}_{2}$ reacts with calcium hydroxide and high alkali C-S-H to form new hydration products until they all have been consumed. Then the generated low alkali C-S-H gel gradually cumulate around the GP and firmly link GP and the matrix to improve the strength.

\subsection{Mercury intrusion porosimetry (MIP)}

GP can significantly influence porosity, pore size distribution and pore shape of cement paste. Fig. 2 shows that the total pore volume of GP pastes is a little higher than that of pure cement paste. The hydration reactivity of GP is lower than that of cement (especially at early ages), thus generating fewer hydration products to fill the pores. But, GP changes the pore distribution of the paste. According to the pore size distribution, the pores in the paste are divided into four categories: aerogel pores $(<5 \mathrm{~nm})$, mesopores $(5-50 \mathrm{~nm})$, medium capillary pores $(50-95 \mathrm{~nm})$ pores and large capillary pores $(>95 \mathrm{~nm})$ [18]. Fig. 3 shows the pore size distribution percent of three samples at 28 and 90 days. With the increase of curing age, the capillary pores decrease and turn into mesopores. The increase of total volume and the decline of capillary pores suggest that the rise of porosity attribute to the increase of pores smaller than $50 \mathrm{~nm}$ and thus improves the pore size distribution effectively, which will be beneficial to the strength and durability of the cementbased materials.

\subsection{X-ray diffraction (XRD)}

Fig. 4 and Fig. 5 show the hydration products of pastes under different curing conditions. Compared with the pure cement, no new diffraction peaks appears for the pastes containing GP, illustrating that GP does not modify the hydration products of the binder. The intensity of calcium hydroxide diffraction peak falls significantly with the increase GP content [19]. This may be caused by the pozzolanic reaction of GP, which consumes some $\mathrm{Ca}(\mathrm{OH})_{2}$ [1]. In addition, cement content, which plays a dominant role in the generation of $\mathrm{Ca}(\mathrm{OH})_{2}$ in the hardened pastes, decreases with the increase of GP content, contributing to the decline in number of generated calcium hydroxide.

When composite cementitious materials containing GP contacts with water, the clinker reacts preferentially and forms C-S-H gel, $\mathrm{Ca}(\mathrm{OH})_{2}$ and $\mathrm{C}-\mathrm{A}-\mathrm{H}$ etc. [20]. GP dilutes the concentration of cement, relatively improving the effective water for the cement hydration in the system. So, the reaction rate of pastes containing GP exceeds the pure cement at early hydration stage. In addition, the concentration of $\mathrm{Ca}^{2+}$ decreases because of the relative increase of effective water, which delays the saturation of $\mathrm{Ca}^{2+}$ and the induction period of hydration. As $\mathrm{Ca}(\mathrm{OH})_{2}$ generates constantly, the $\mathrm{pH}$ value of the liquid phase increases. The dissociated hydroxide ions destruct and dissolve the silica vitreous, rupturing $\mathrm{Si}-\mathrm{O}-\mathrm{Si}$ to form $\mathrm{Si}$ $\mathrm{OH}$, leading to disaggregation caused by rupture of oxobridged oxygen bond in vitreous with irregular network structure. The process is as follows.

$\equiv \mathrm{Si}-\mathrm{O}-\mathrm{Si} \equiv+\mathrm{OH}^{-} \longrightarrow \equiv \mathrm{Si}-\mathrm{O}^{-}+\mathrm{HO}-\mathrm{Si} \equiv$. 


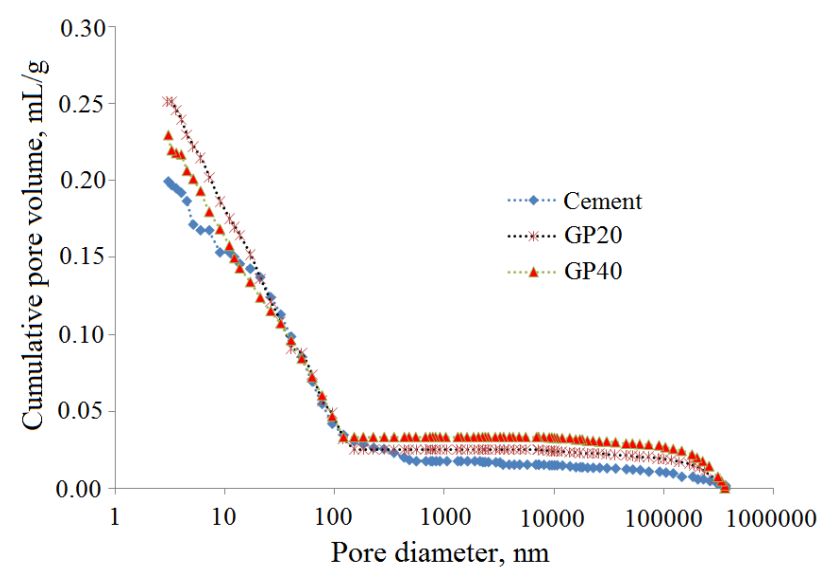

a

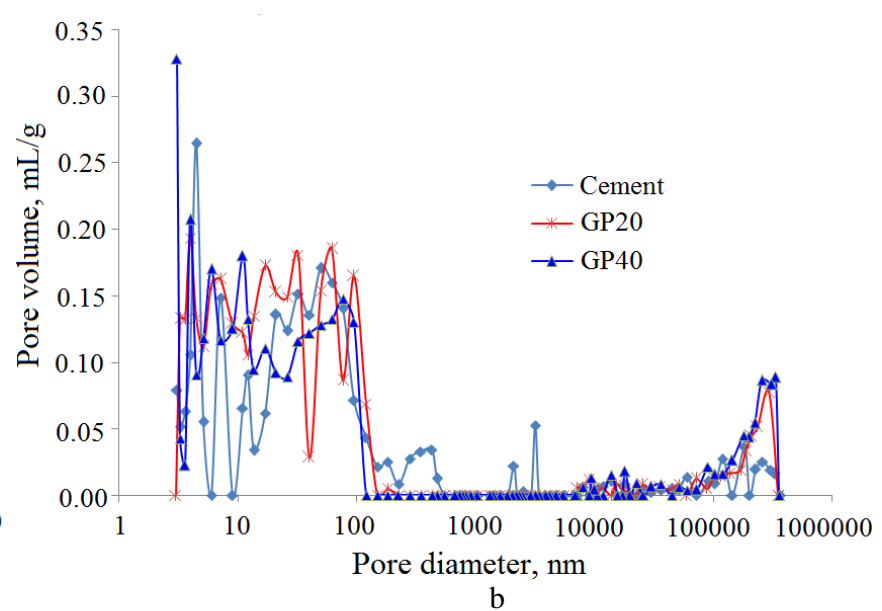

$\mathrm{b}$

Fig. 2. Effect of waste glass powder on pore size distributions of pastes at 28 days: a - cumulative curves; $b$-differential curves

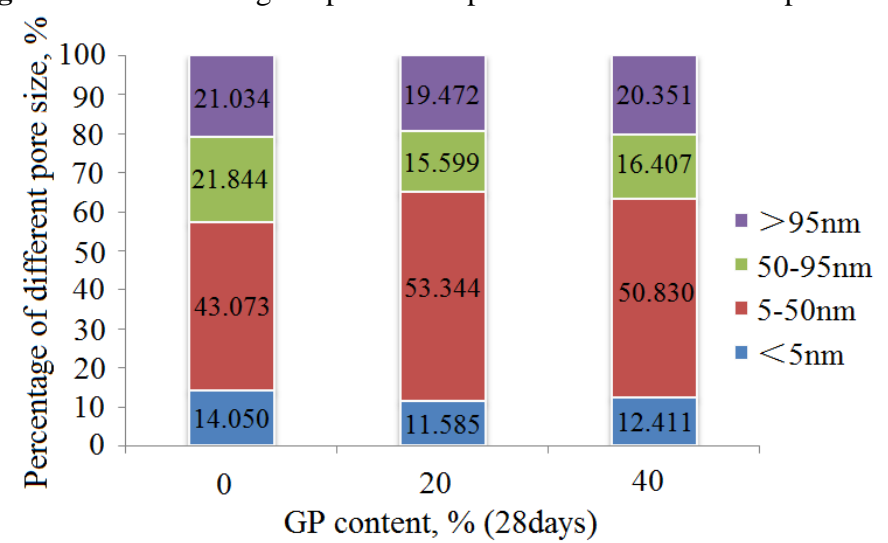

a

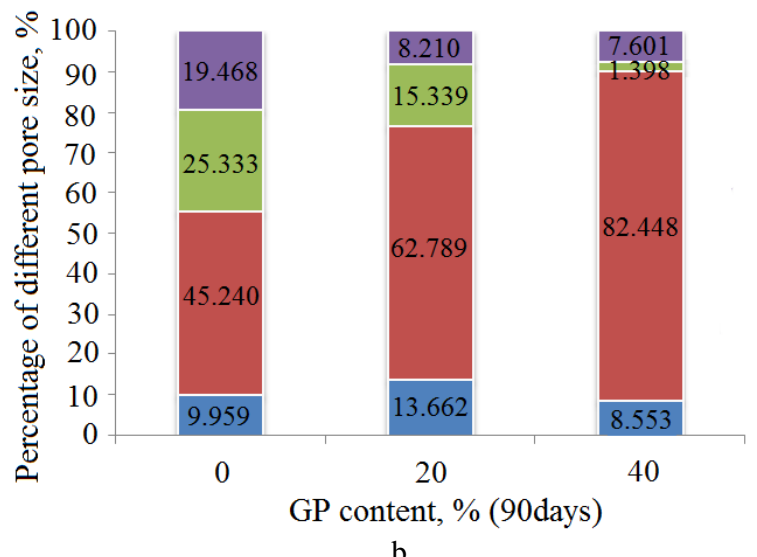

b

Fig. 3. Effect of GP content on pore size distribution of the pastes at: $a-28$ days and b-90 days

Simultaneously, $\mathrm{SiO}_{4}{ }^{4-}, \mathrm{Ca}^{2+}$ and $\mathrm{Na}^{+}$are accumulating to reach a new saturation state, the process must be long enough to make the products interplay of various ions precipitate to realize the nucleation, growth of hydrates and the formation of a mesh structure. The process can be illustrated by Eq. 2:

$$
x \mathrm{Ca}(\mathrm{OH})_{2}+\mathrm{SiO}_{2}+m \mathrm{H}_{2} \mathrm{O} \rightarrow \mathrm{xCaO} \cdot \mathrm{SiO}_{2} \cdot n \mathrm{H}_{2} \mathrm{O} \text {. }
$$

When the concentration of $\mathrm{Ca}^{2+}$ is relatively insufficient for $\mathrm{SiO}_{4}{ }^{4-}$, the cement hydrates C-S-H gel which has high $\mathrm{pH}$ value may participate in reaction to form hydrates with a low $\mathrm{Ca} / \mathrm{Si}$ ratio [21]:

$$
\begin{aligned}
& x(1.5-3.0) \mathrm{CaO}_{2} \cdot \mathrm{SiO}_{2} \cdot n \mathrm{H}_{2} \mathrm{O}+y \mathrm{SiO}_{2} \rightarrow \\
& z(0.8-1.5) \mathrm{CaO} \cdot \mathrm{SiO}_{2} \cdot n \mathrm{H}_{2} \mathrm{O} .
\end{aligned}
$$

According to the principle of chemical equilibrium and the dissolution equilibrium theory, the precipitation of low alkali C-S-H gel consumes large quantities of ions from liquid phase, which promotes the hydration of cement and the dissolution of GP to ensure the persistence of the reaction.

The intensity of the characteristic diffraction peak of $\mathrm{Ca}(\mathrm{OH})_{2}$ in pure cement paste increases obviously after steam cured, which shows that high temperature can promote the hydration of cement effectively [22]. But the characteristic diffraction peak of CAH near $12^{\circ}$ for pastes with and without GP almost disappears. This may be attributed to the conversion of calcium aluminate hydrates under high temperature. When the content of gypsum in Portland cement is low, it's possible to discern unhydrated
$\mathrm{C}_{3} \mathrm{~A}$ in the systerm. The existing unhydrated $\mathrm{C}_{3} \mathrm{~A}$ can react with satureted sodium hydroxide solution [23]:

$\mathrm{C}_{3} \mathrm{~A}+\mathrm{CH}_{12}+\mathrm{H}=\mathrm{C}_{4} \mathrm{AH}_{13}$.

$\mathrm{C}_{4} \mathrm{AH}_{13}$ can exist in alkalescent medium containing $\mathrm{CH}$ in ambient temperature. However, the metastable $\mathrm{C}_{4} \mathrm{AH}_{13}$ inclines to translate into $\mathrm{C}_{3} \mathrm{AH}_{6}$ under high temperature [23]. The transformation process is as follows:

$\mathrm{C}_{4} \mathrm{AH}_{13}+\mathrm{C}_{2} \mathrm{AH}_{8}=2 \mathrm{C}_{3} \mathrm{AH}_{6}+9 \mathrm{H}$.

From Fig. 4 and Fig. 5 , it is obvious that the intensity o $\mathrm{f}$ the calcium hydroxide diffraction peak for samples cured $40{ }^{\circ} \mathrm{C}$ is higher than that cured at normal temperature.

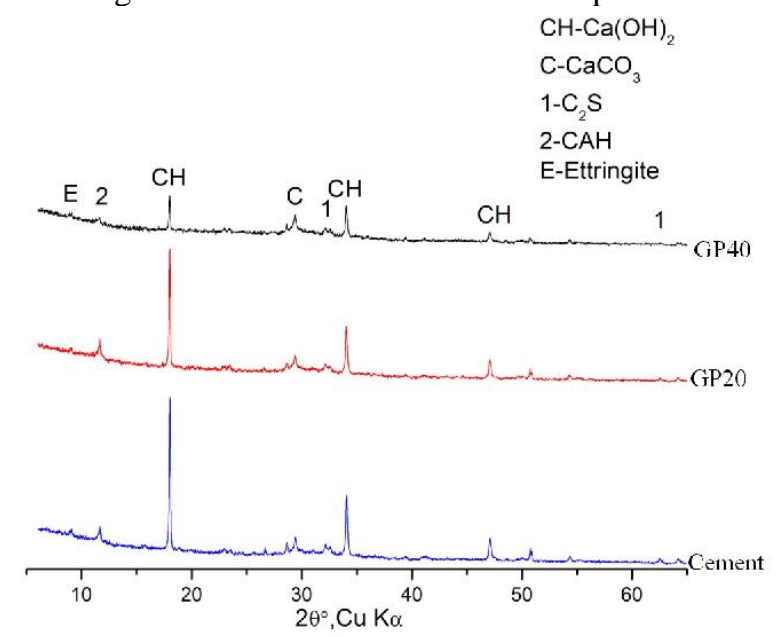

Fig. 4. XRD patterns of the pastes with and without glass powder at 28 days under standard curing condition 
Elevated temperature can accelerate both pozzolanic reaction of GP that consumes $\mathrm{CH}$ and the hydration of cement which can generate $\mathrm{CH}$. The amount of $\mathrm{CH}$ in blended binder incorporating GP depends on aformentioned two processes. All of these possible reasons cause the variation of $\mathrm{Ca}(\mathrm{OH})_{2}$ characteristic diffraction peak, and the total $\mathrm{Ca}(\mathrm{OH})_{2}$ content in the systerm.

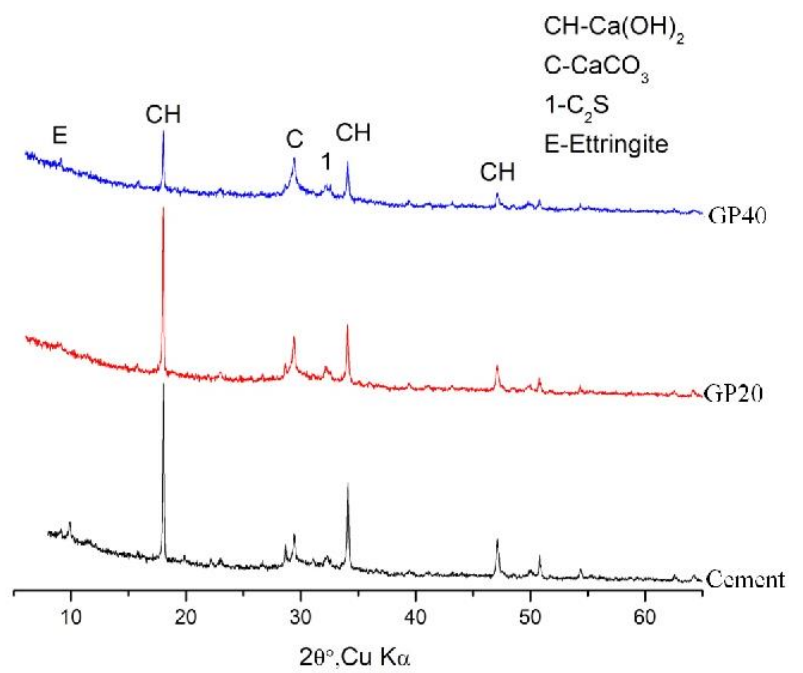

Fig. 5. XRD patterns of the pastes with and without glass powder at 28 days under $40^{\circ} \mathrm{C}$ steam curing condition

\subsection{Scanning electron microscopy (SEM)}

Fig. 6 a shows hydration products of the pure cement paste. Calcium silicate hydrate possesses a fibrous morphology, presenting itself radiated and agglomerated. It's hard to discern the needle-like ettringite from C-S-H. These hydrates overlap and connect with each other, binding unhydrated particles to form a mesh structure, which forms the skeleton of the system. The microstructure of the pure cement pastes at 28 days is porous and loose. Unlike Fig. 6 a, Fig. 6 b shows that pastes containing $20 \%$ GP are a little denser, and it's difficult to identify hydrates in some parts. This may be attributed to that the smaller particles and wider grading distribution of GP could increase the stacking density of binders, decreasing void content in hydrates. Moreover, C-S-H gel generated from the pozzolanic reaction of GP decreases the pores volume. The shape of the C-S-H gel in pastes containing GP is abnormal short column and lamelliform, which differs from those in pure cement specimens. Fig. $6 \mathrm{c}$ displays that the microstructure of the pastes containing $40 \% \mathrm{GP}$ is much denser. There is an obvious reaction ring along the GP. Different from ASR, there is no crack in or near the reaction ring. Pozzolanic reaction is found at the edge of particles. The generated $\mathrm{C}-\mathrm{S}-\mathrm{H}$ gel constantly fills the interfacial transition zone to ensure the consolidation of GP particles within the hydrate matrix.

\section{CONCLUSIONS}

1. GP can be used as mineral admixture in the cementbased materials. Compared with pure cement paste, the early strength of pastes containing GP is low. GP is temperature sensitive and has a higher tendency to participate in pozzolanic reaction under high temperature. GP with lower average particle size exhibits higher pozzolanic reactivity, thus improves the strength of the paste matrix.

2. The hydration process of composite cementitious material containing GP is similar to that of pure cement. With the increase of GP content in the composite cement, the occurring time of second exothermic improves, but the value of second exothermic peak and the cumulative hydration heat reduce.

3. The pore structure of pastes containing GP is much denser. The pores in the pastes containing GP become finer.

4. GP does not modify the type of the hydration products. GP pastes contain less $\mathrm{Ca}(\mathrm{OH})_{2}$ because of pozzolanic reaction, but elevated temperature can promote the generation of $\mathrm{CH}$ in the early stage.

5. GP pastes contain much more $\mathrm{C}-\mathrm{S}-\mathrm{H}$ gel, resulting in a denser matrix and higher strength. The reaction ring along hydrated GP can be discerned in paste containing $40 \%$ GP. The pozzolanic reaction of GP with high fineness enhanced the interfacial transition zone to avoid ASR.

\section{Acknowledgments}

This project is funded by the National Natural Science Foundation of China (51208391), Technology Project of Hubei Highway Administration (2013-731-2-3), and the Opening Funds of Guangxi Key Laboratory of New Energy and Building Energy Saving (15-J-22-4-001).

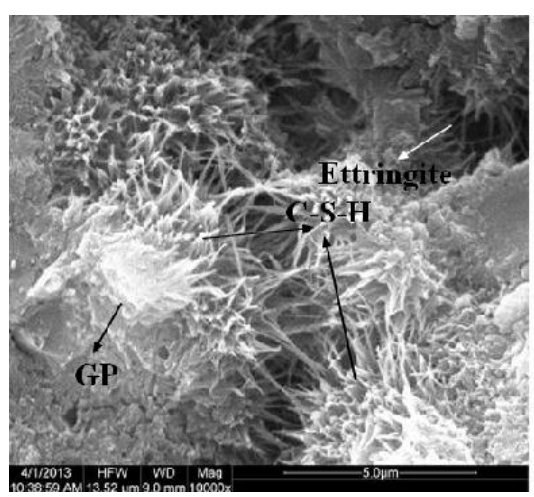

a

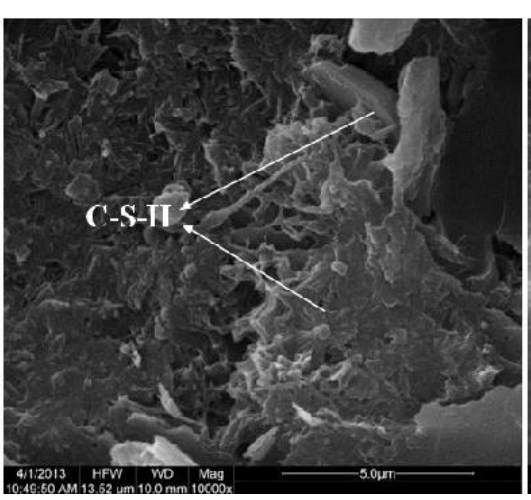

$\mathrm{b}$

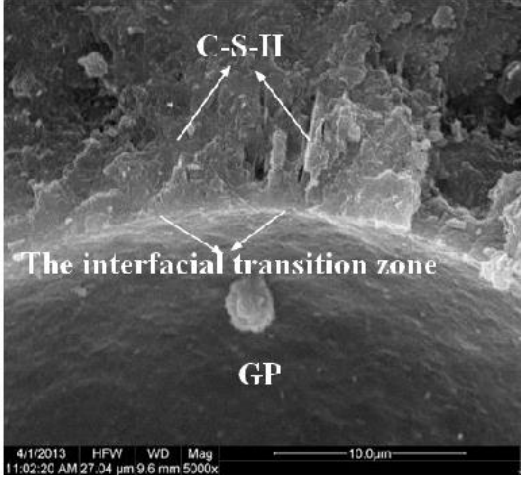

c

Fig. 6. a-SEM image of cement at 28 days; b-SEM image of GP20 at 28 days; c-SEM image of GP40 at 28 days 


\section{REFERENCES}

1. Schwarz, N., Cam, H., Neithalath, N. Influence of a Fine Glass Powder on The Durability Characteristics of Concrete and Its Comparison to Fly Ash Cement and Concrete Composite 30 (3) 2008: pp. 486-496.

2. Qu, C., Gao, Z.Y., Liu, S.H., Zhao, D., Zeng, J.C., Huang, C.M. Application Research of Obsolete Glass Dust Used in RPC Concrete 55 (08) 2011: pp. 82-84.

3. Liu, S.H., Xie, G.S., Wang, S. Effect of Curing Temperature on Hydration Properties of Waste Glass Powder in Cement-Based Materials Journal of Thermal Analysis and Calorimetry 119 (1) 2015: pp. 47-55. http://dx.doi.org/10.1007/s10973-014-4095-6

4. Meyer, C. Recycled Glass-From Waste Material to Valuable Resource Proceedings of the International Symposium: Recycling and Reuse of Glass Cullet 2001: pp. $1-10$.

5. Ling, T.C., Poon, C.S., Wong, H.W. Management and Recycling of Waste Glass in Concrete Products: Current Situations in Hong Kong Resources Conservation and Recycling 70 (1) 2013: pp. 25-31. http://dx.doi.org/10.1016/j.resconrec.2012.10.006

6. Shi, C.J., Zhen, K.R. A Review on the Use of Waste Glass in the Production of Cement and Concrete Resources Resources Conservation and Recycling 52 (2) 2007: pp. $234-247$.

7. Kim, J., Yi, C.K., Zi, G. Waste Glass Sludge as a Partial Cement Replacement in Mortar Construction and Building Materials 75 (2) 2015: pp. $242-246$.

8. Kou, S.C., Poon, C.S. Properties of Self-Compacting Concrete Prepared with Recycled Glass Aggregate Cement and Concrete Composite 31 (1) 2009: 107-113.

9. Rachida, I., Martin, C., Arezki, T.H. Use of Glass as ASR Inhibitor in Glass Aggregate Mortars Construction and Building Materials 24 (12) 2010: pp. 1309-1312.

10. Nwaubani, S.O., Poutos, K.I. The Influence of Waste Glass Powder Fineness on the Properties of Cement Mortars International Journal of Applied Innovation Engineering Management 2(2) 2013: pp. 110-116.

11. Shao, Y.X., Lefort, T., Moras, S., Rodriguez, D. Studies on Concrete Containing Ground Waste Glass Cement and Concrete Research 30 (1) 2000: pp. 91-100.
12. Rachida, I., Martin, C., Arezki, T.H. Pozzolanic Properties of Fine and Coarse Color-Mixed Glass Cullet Cement and Concrete Composite 33 (1) 2011: 19-29. http://dx.doi.org/10.1016/j.cemconcomp.2010.09.013

13. Federico, L.M., Chidiac, S.E. Waste Glass as a Supplementary Cementitious Material in Concrete - Critical Review of Treatment Methods Cement and Concrete Composite 31 (5) 2009: pp. 606-610.

14. Rachida, I., Martin, C., Arezki, T.H. Use of Fine Glass as ASR Inhibitor in Glass Aggregate Mortars Construction and Building Materials 24 (12) 2010: pp. 1309-1312.

15. Taylor, H.F.M. Cement Chemistry ( $2^{\text {nd }}$ edition). Thomas Telford, London, 1997. http://dx.doi.org/10.1680/cc.25929

16. Mohammadreza, M., Kyle, A.R. Effect of Curing Temperature and Glass Type on The Pozzolanic Reactivity of Glass Powder Cement and Concrete Research 58 (1) 2014: pp. $103-111$.

17. Rachida, I., Martin, C., Arezki, T.H. Pozzolanic Properties of Fine and Coarse Color-Mixed Glass Cullet Cement and Concrete Composite 33 (1) 2011: pp. 19-29. http://dx.doi.org/10.1016/j.cemconcomp.2010.09.013

18. Metha, P.K., Monterio, P.J. Concrete, Microstructure, Properties and Materials. McGraw-Hill, London, UK, 2003.

19. Dyer, T.D., Dhir, R.K. Chemical Reactions of Glass Cullet Used as Cement Component Journal of Materials in Civil Engineering 13 (6) 2001: pp. 412-419.

20. Yuan, R.Z. Cementitious Material Science. Wuhan University of Technology Press. Wuhan, 1996.

21. Lothenbach, B., $\quad$ Scrivener, K., Hooton, R.D. Supplementary Cementitious Materials Cement and Concrete Research 41 (12) 2011: pp. 1244-1256. http://dx.doi.org/10.1016/j.cemconres.2010.12.001

22. Shi, C.J., Wu, Y.Z., Riefler, C. Characteristics and Pozzolanic Reactivity of Glass Powders Cement and Concrete Research 35 (5) 2005: 987-993. http://dx.doi.org/10.1016/j.cemconres.2004.05.015

23. Yuan, R.Z. Cementitious Material Science. Wuhan university of technology press, Wuhan, 1996. 